\title{
Optimization of Rail Profiles to Improve Vehicle Running Stability in Switch Panel of High-Speed Railway Turnouts
}

\author{
Ping Wang, ${ }^{1,2}$ Xiaochuan Ma, ${ }^{1,2}$ Jian Wang, ${ }^{1,2}$ Jingmang Xu,, ${ }^{1,2}$ and Rong Chen ${ }^{1,2}$ \\ ${ }^{1}$ MOE Key Laboratory of High-Speed Railway Engineering, Southwest Jiaotong University, Chengdu 610031, China \\ ${ }^{2}$ School of Civil Engineering, Southwest Jiaotong University, Chengdu 610031, China \\ Correspondence should be addressed to Jingmang Xu; mang080887@163.com
}

Received 31 October 2016; Accepted 23 January 2017; Published 12 February 2017

Academic Editor: Gen Q. Xu

Copyright (c) 2017 Ping Wang et al. This is an open access article distributed under the Creative Commons Attribution License, which permits unrestricted use, distribution, and reproduction in any medium, provided the original work is properly cited.

\begin{abstract}
A method for optimizing rail profiles to improve vehicle running stability in switch panel of high-speed railway turnouts is proposed in this paper. The stock rail profiles are optimized to decrease the rolling radii difference (RRD). Such characteristics are defined through given rail profiles, and the target rolling radii difference is defined as a function of lateral displacements of wheel set. The improved sequential quadratic programming (SQP) method is used to generate a sequence of improving profiles leading to the optimum one. The wheel-rail contact geometry and train-turnout dynamic interaction of the optimized profiles and those of nominal profiles are calculated for comparison. Without lateral displacement of wheel set, the maximum RRD in relation to a nominal profile will be kept within $0.5 \mathrm{~mm}-1 \mathrm{~mm}$, while that in relation to an optimized profile will be kept within $0.3 \mathrm{~mm}-0.5 \mathrm{~mm}$. For the facing and trailing move of vehicle passing the switch panel in the through route, the lateral wheel-rail contact force is decreased by $34.0 \%$ and $29.9 \%$, respectively, the lateral acceleration of car body is decreased by $41.9 \%$ and $40.7 \%$, respectively, and the optimized profile will not greatly influence the vertical wheel-rail contact force. The proposed method works efficiently and the results prove to be quite reasonable.
\end{abstract}

\section{Introduction}

Railway turnouts are essential components in railway applications as they can provide flexibility for traffic operations, enabling vehicles to change among the tracks. They are made up of a switch panel, a crossing panel, and a closure panel [1]. To realise wheel transfer from a stock rail to a switch rail, switch rail profiles are designed with variation along the switch panel and combined with the stock rail. The variation in rail profiles changes boundary conditions of wheel-rail contact, resulting in a contact patch that is no longer elliptical. In railway turnouts, the combination of a switch rail and a stock rail to bear wheel loads together makes multipoint contact more common. Situations of nominal wheel-rail contact are disturbed when a vehicle passes through a turnout, potentially resulting in severe impact loads. Material loss, rolling contact fatigue, and accumulated plastic deformations are common damage mechanisms that further disturb nominal contact conditions [2]. Due to this phenomenon, railway turnouts account for the largest contribution of reported faults and require more maintenance than other components of railway networks.

The design of rail and wheel profiles is a fundamental problem, and various approaches were developed to obtain a satisfactory combination of wheel and rail. Typically, a rail or wheel profile was designed using the trial-and-error approach, but during the last few decades, a number of efforts have been made using numerical methods in the design process. The main idea in optimizing rail and wheel profiles of ordinary tracks is based on wheel-rail contact characteristics such as rolling radii difference (RRD) of wheel set. Shevtsov et al. [3] established models to design an optimal wheel profile by minimizing the difference between the target and the actual RRD function, and three approaches for choosing a target RRD function were suggested; they also used the same method to design a wheel profile by considering $\mathrm{w} / \mathrm{r}$ rolling contact fatigue (RCF) and wear; the paper shows that the RRD of wheel set on the straight line should be as low as possible in order to ensure the lateral running stability of the wheel set [4]. Jahed et al. [5] proposed a 
computationally efficient optimization algorithm that works with five design variables using a method targeting the RRD function, and they put forward a cubic spline interpolation method to ensure the convexity and monotony of wheel profiles. Markine et al. [6] designed an optimal wheel profile based on geometrical wheel-rail contact characteristics, such as RRD. They chose an optimization method called multipoint approximations based on response surface fitting (MARS) as a numerical technique. Other efforts have been made based on different optimal targets. Polach [7] studied the interrelationship between the nominal contact angle, conformity, and equivalent conicity, and this relationship was considered in the method for wheel profile design. Shen et al. [8] developed a method for generating new wheel profiles using the contact angle function between wheels and rails. Cui et al. [9] used a conventional optimization procedure to obtain wheel profiles that placed the weighted $\mathrm{w} / \mathrm{r}$ gap as the objective function, and they put forward a new wheel profile design method to reduce the hollow wear by seeking an optimization match of the wheel profiles, the vehicle's suspension systems, and the wear behaviour of wheels in service [10]. Smallwood et al. [11] suggested a method to modify transverse rail profiles in order to reduce contact stress and used theoretical methods to investigate the effect of profile changes on contact stress and conicity. Novales et al. [12] proposed a new general methodology for improving wheel profiles in relation to certain physical phenomena that arise during the running of the vehicle over tracks, and the methodology was based on the genetic algorithm technique. Ignesti et al. [13] presented an innovative wheel profile optimization procedure, specifically designed with the aim of improving the wear and stability of vehicles. Lin et al. [14] proposed a multiobjective optimization model of wheel profile to reduce the wheel wear of electric multiple units. For the curved track, some optimum design methods for asymmetric profiles are often used to reduce the wear of wheel flange and rail side. Choi et al. $[15,16]$ proposed an optimum design procedure for asymmetric railhead profiles by minimizing the wear and fatigue on curved tracks. Zhai et al. [17] put forward a design methodology of rail asymmetricgrinding profiles based on the principle of a low dynamic interaction of wheel-rail.

The optimal studies of railway turnouts are less than ordinary track because the w/r contact relationship of railway turnouts is more complex. At present, the main optimal idea of railway turnouts focuses on the geometry parameters, such as the height of switch rail, the thickness of nose rail, and the track gauge design of switch panel. Pålsson and Nielsen [18] proposed a methodology for the optimization of a prescribed track gauge variation in the switch panel of a railway turnout, the aim of which is reducing rail profile degradation. Also, Pålsson et al. presented some methods for profile geometry optimization of switch rail and nose rail by using a genetic type optimization algorithm; the purpose of these efforts is to improve the dynamic interactions between wheel and rail and minimize contact pressure and accumulated damage of rails $[19,20]$. To improve the dynamic behaviour of turnout crossings, Wan et al. [20] proposed a numerical optimization method to minimize RCF damage and wear in the crossing panel by varying the nose rail shape. Nicklisch et al. [21] represented the geometry of a designed track gauge variation in the switch panel in a parametric way to find the means of improving the switch panel design. Bugarín and García DíazDe-Villegas [22] studied the problem of turnout optimization with respect to impact loads occurring during the negotiation of the main line, proposing a gauge widening method in a switch panel. These optimal efforts can improve the dynamic behaviour of railway turnouts to minimize RCF damage and wear.

For the switch panel of railway turnout, the variable crosssection rails will lead to the RRD of wheel set. The RRD of wheel set is not always the same at different positions along the longitudinal direction of the railway line, which can cause further lateral motion of the wheel set, decrease of vehicle running stability, severe dynamic vehicle-turnout interaction, and damage to wheels and rails. In this paper, an optimal method in switch panel of high-speed railway turnouts is present based on the RRD function, and the optimal principle is to minimize the rolling radii difference of wheel set as far as possible. Based on a standard design CN601100-1:18 turnout (curve radius $1100 \mathrm{~m}$; turnout angle 1:18), the rail profiles are optimized by this method. The wheel-rail contact geometry and dynamic interaction between vehicle and turnout of the optimized profiles and those of nominal profiles are calculated for comparison.

\section{Optimization of Rail Profiles}

2.1. Rolling Radii Difference in Switch Panel. For switch panel of railway turnout, the variable cross-section rails will inevitably cause RRD of wheel set. As shown in Figure 1, in the switch panel of railway turnout in the through route, without lateral displacement of wheel set, the wheel-rail contact position changes with the variable cross-section switch rails. The rolling radius of the wheel at both sides is different; therefore, the rolling distances of the wheel at both sides are different at the same time and the wheel set moves under the action of lateral creep force. The lateral motion of wheel set will reduce the vehicle running stability at a high-speed level. In Figure 1, $x y z$ refers to the coordinate system of the centreline; the $x$-axis and $y$-axis refer to the longitudinal direction and lateral direction of the railway line, and $z$-axis refers to the vertical direction.

The varied profiles lead to differences in rolling radius of wheel set. The normal wheel-rail contact situations are disturbed when wheels transfer between two rails in railway turnouts (e.g., the stock rail and switch rail), sometimes resulting in severe impact loads. Dynamic vehicle-turnout interaction between train and turnout is a time variant process and is more complex than plain line due to the lateral translations of wheel set and varied rail profiles, thus having a significant effect on the dynamic interaction between train and turnout, which may influence the vehicle running stability. The rolling radii difference in switch panel can be expressed as follows:

$$
\Delta r=\left|r_{r}-r_{l}\right|
$$




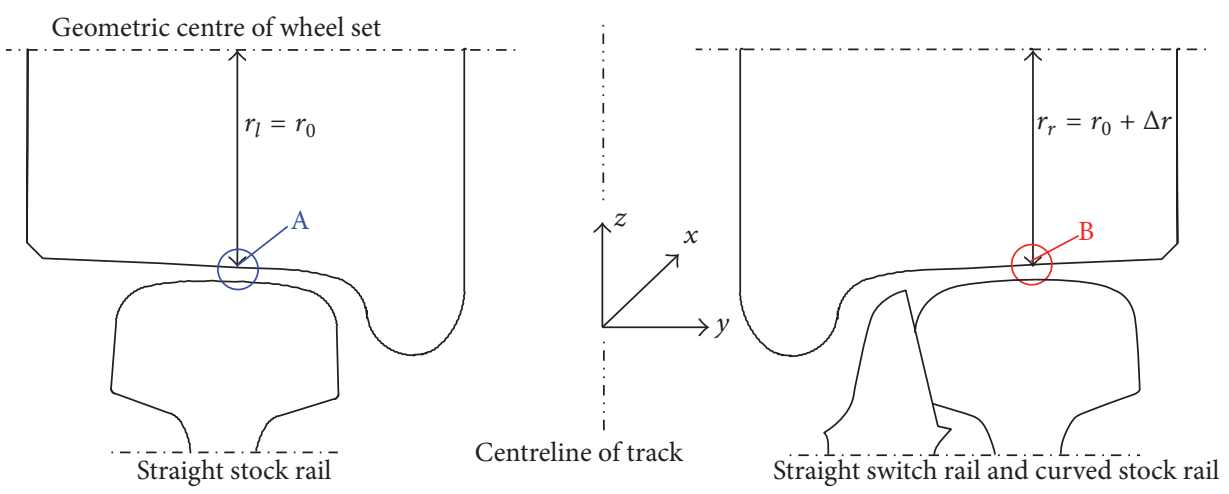

FIGURE 1: Rolling radii in switch panel of railway turnout. Points A and B refer to the wheel-rail contact positions. $r_{l}$ and $r_{r}$ are rolling radii of the wheels at both sides. $r_{0}$ refers to the nominal rolling radius of the wheel and $\Delta r$ is RRD of the wheel set.

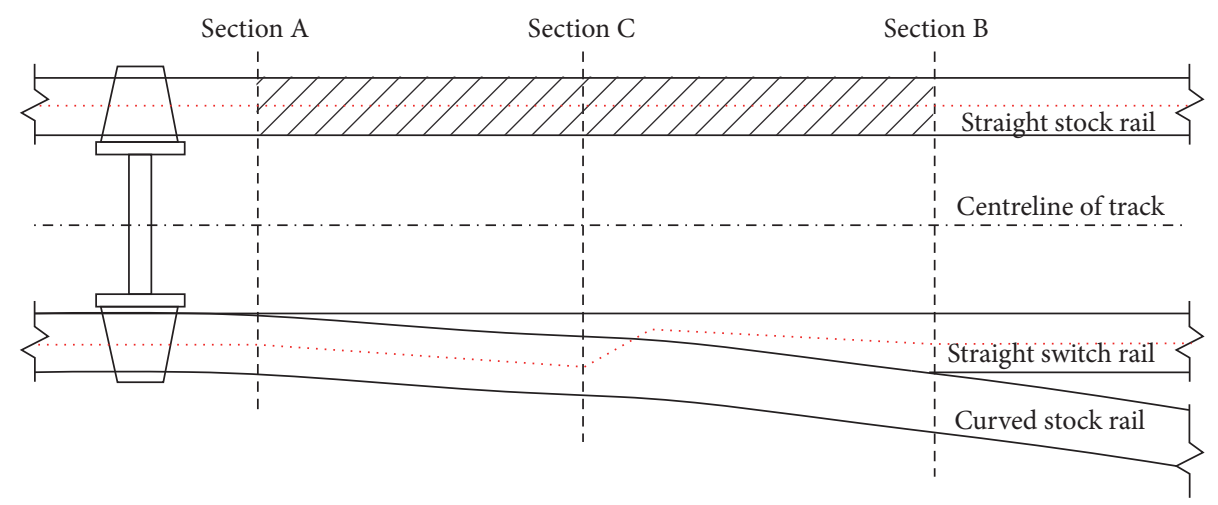

FIGURE 2: Optimization plan of rail profiles in switch panel. The red dotted lines refer to the path line of wheel-rail contact points.

where $r_{r}$ is the rolling radius of the wheel on the side of the switch rail and $r_{l}$ is the rolling radius of the wheel on the opposite side of the track.

2.2. Optimization Plan. As shown in Figure 2, the variable cross-section rails lead to RRD of the wheel set between Section A and Section B even without the lateral displacement of wheel set; therefore, this region can be taken as the optimization range. Section $A$ is the point of switch rail and is the starting point of the variable cross-section rails. Section $B$ is the end point of the variable cross-section rails. Within the optimization region, the RRD of wheel set is not always the same at different positions along the longitudinal direction of the railway line but reaches the peak value at Section C; therefore, Section $\mathrm{C}$ is selected as the control position on the optimization plan. The rail profiles of Section A and Section B are not optimized, and the rail profile of the straight stock rail at Section $\mathrm{C}$ is optimized using the method which described in the subsequent sections. The rail profile between Section A and Section C as well as that between Section C and Section B can be obtained according to the linear interpolation method.

Section $\mathrm{C}$ is the position before the wheels transfer from the stock rail to the switch rail when vehicle passes the switch panel with the facing move in the through route; the calculation method of the position is as follows:
(1) Calculate the positions of wheel-rail contact points per $0.1 \mathrm{~m}$ along the longitudinal direction of the railway line from Section A to Section B. Since the lateral displacement of the wheel set is low when vehicle passes the switch panel in the through route, the situation of wheel flanges clinging to rails is neglected; therefore, the lateral displacement of wheel set is selected from $-8 \mathrm{~mm}$ to $8 \mathrm{~mm}$.

(2) When all of wheel-rail contact points of a position are located on the stock rail and at the next position all or part of contact points are transferred from the stock rail to the switch rail, then the position can be considered as Section C.

Considering the influence law of variable cross-section rails of the switch panel on RRD of wheel set along the longitudinal direction of the railway line, the rail profile of the straight stock rail at Section $\mathrm{C}$ can be selected as the object to be optimized. The rail profile between Section A and Section C as well as that between Section B and Section C can be obtained according to the linear interpolation method. This optimization plan can help to reduce RRDs of wheel sets for different positions of the switch panel as much as possible.

2.3. Optimization Method. The optimization region is located on the railhead of the straight stock rail. For example, in the 


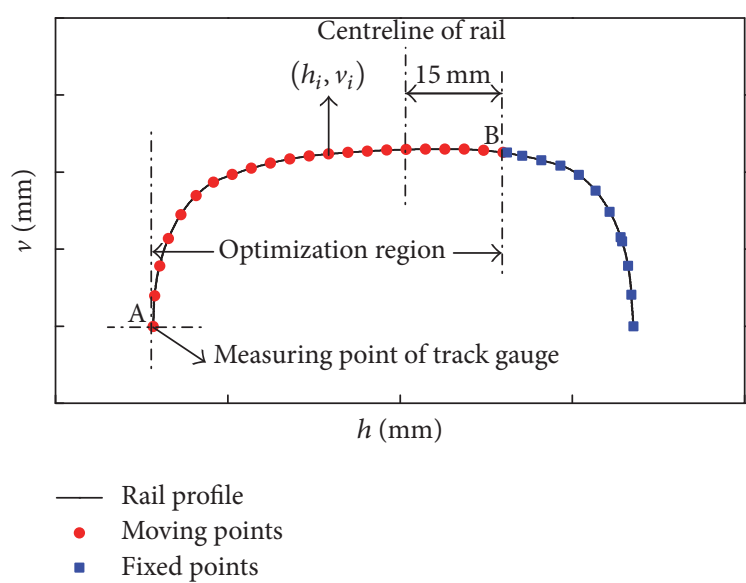

FIgURE 3: Optimization region of rail profile.

optimized profile design of a straight stock rail (Figure 3), the optimization region of the rail profile is from $A$ to $B$. The range from $\mathrm{A}$ to $\mathrm{B}$ relates to the region with possible wheel-rail contact, where Point A is the measuring point of track gauge and Point $B$ is a position $15 \mathrm{~mm}$ away from the centreline of the railhead on the right side. The position of these moving points $\left(h_{i}, v_{i}, i=1,2, \ldots, n\right)$ can be varied in order to get the optimized profile. Respectively, $h_{i}$ and $v_{i}$ are the lateral and vertical coordinates of the moving points. To simplify modelling, the abscissa of each moving point $h_{i}$ $(i=1,2, \ldots, n)$ is selected as a constant, and the vertical coordinates of each moving point $v_{i}$ are considered to be varied. Moreover, $v_{i}$ is chosen as a variable in the optimization problem. The rail profile can be expressed as $f\left(v_{i}\right)$.

When the lateral displacement of wheel set is $y_{k}$, the positions of wheel-rail contact points at both sides can be obtained based on the principle of the tracing line method [23]. The position of wheel-rail contact point at the right side is $C_{r, k}\left(y_{r, k}, z_{r, k}\right)$, and the position of wheel-rail contact point at the left side is $C_{l, k}\left(y_{l, k}, z_{l, k}\right)$. The rolling radii of the wheels can be calculated according to the positions of wheel-rail contact points. The RRD function of wheel set can be defined as

$$
\Delta r_{k}=\left|r_{r, k}-r_{l, k}\right|
$$

where $r_{r, k}$ and $r_{l, k}$ are the rolling radii of the wheels at both sides. The rolling radii of the wheels relate to the positions of wheel-rail contact points which are dependent on the lateral wheel set displacement and wheel-rail profiles, so the RRD function of wheel set can also be defined as

$$
\Delta r_{k}=\Delta r_{k}\left(y_{k}, v_{1}, v_{2}, \ldots, v_{n}\right)
$$

Considering the lateral wheel set displacement range, the average RRD function of wheel set can be defined as

$$
S=\frac{\sum_{k=1}^{m} \Delta r_{k}\left(y_{k}, v_{1}, v_{2}, \ldots, v_{n}\right)}{m}
$$

where $m$ refers to the number of calculations for lateral wheel set displacement, which can be obtained according to the lateral wheel set displacement range and the calculation step length. Since the probability of lateral wheel set displacement varies, the weight coefficient $w$ should be adopted for controlling the influence of different lateral displacement of wheel set on function S. Supposing that the probability of lateral wheel set displacement meets the law of normal distribution $\left(\mu, \sigma^{2}\right)$, then according to [9], the lateral wheel set displacement has the highest probability of being less than $4 \mathrm{~mm}$. So in the normal distribution curve of lateral wheel set displacement, the mathematical expectation $\mu$ is 0 , and the standard deviation $\sigma$ is 4 . The weight coefficient in relation to different lateral wheel set displacement results can be expressed as

$$
w= \begin{cases}0.68, & \left|y_{i}\right| \in[0,4] \\ 0.27, & \left|y_{i}\right| \in(4,8] \\ 0.05, & \left|y_{i}\right| \in(8,12] .\end{cases}
$$

When the weight coefficient is considered, the function $S$ can be further expressed as

$$
S=\frac{\sum_{k=1}^{m} w_{j} \Delta r_{k}\left(y_{k}, v_{1}, v_{2}, \ldots, v_{n}\right)}{m}
$$

Since the parameter $y_{k}$ is given in the calculation process, the function $S$ in (6) can be expressed as follows:

$$
S=S\left(v_{1}, v_{2}, \ldots, v_{n}\right) \text {. }
$$

Equation (7) is used as the objective function to find the optimized profile of the rail.

In the process of finding the optimized profile, it is noted that the rail profile is a convex curve. To ensure the authenticity of the rail profile, a constraint equation is used as follows:

$$
G_{i}=v_{i+1}-\frac{v_{i}+v_{i+2}}{2}>0, \quad i=1,2, \ldots, n-2 .
$$

Considering the initial profile of the rail and the capacity of optimization, the boundaries of variables $v_{i}$ are defined as follows:

$$
a_{i} \leq v_{i} \leq b_{i}, \quad i=1,2, \ldots, n
$$

Equations (8) and (9) are used as the constrained functions to find the optimized profile of the rail.

An algorithm is developed using the improved SQP (sequential quadratic programming) method combined with the Quasi-Newton and BFGS (Broyden-Fletcher-GoldfarbShanno) method [24-28]. The optimization problem according to (7)-(9) can be represented as follows:

$$
\begin{aligned}
\min : & S=S\left(v_{1}, v_{2}, \ldots, v_{n}\right) \\
\text { st: } & G_{i}>0 ; \quad a_{i} \leq v_{i} \leq b_{i}, i=1,2, \ldots, n .
\end{aligned}
$$




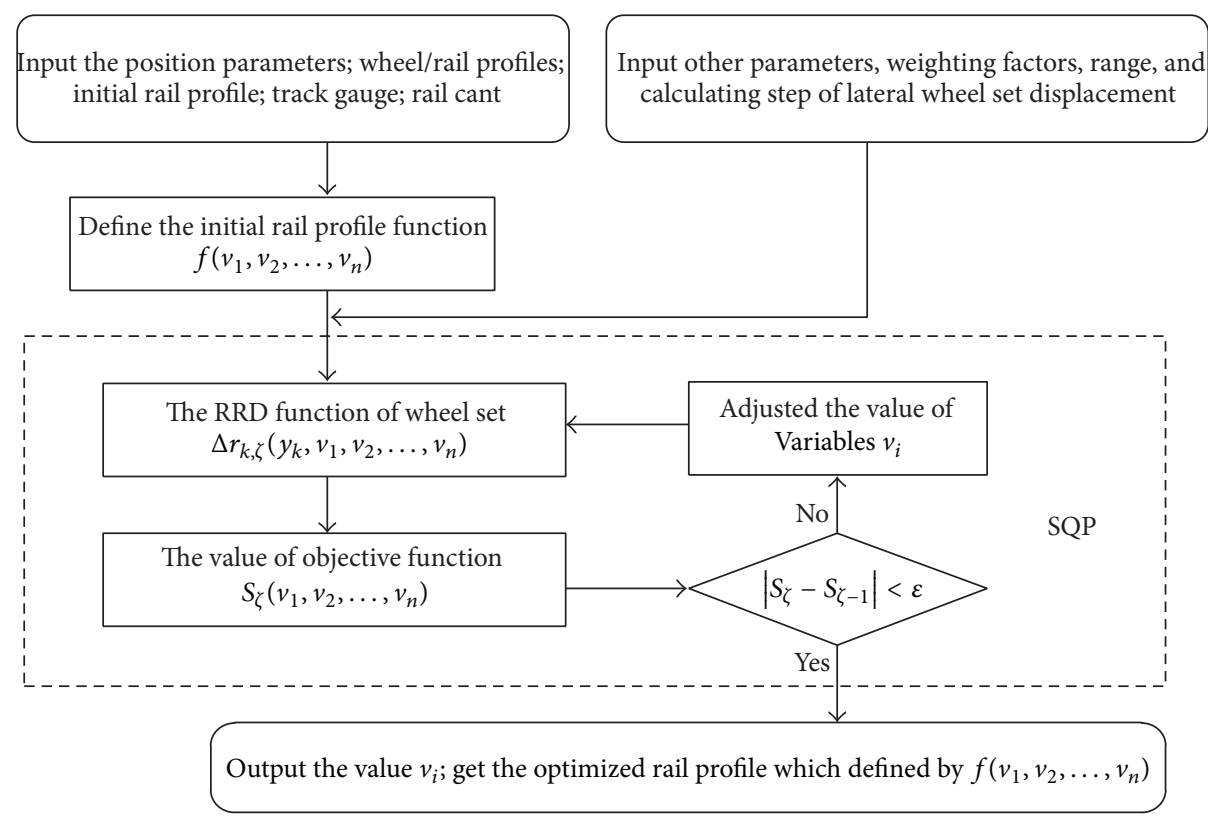

FIGURE 4: Flow chart of the optimization algorithm.

TABLE 1: The parameter values of switch panel.

\begin{tabular}{lcc}
\hline Parameters & Value & Unit \\
\hline Total length of switch rail & 21.449 & $\mathrm{~m}$ \\
Variable cross-section length of switch rail & 10.962 & $\mathrm{~m}$ \\
Track gauge & 1.435 & $\mathrm{~m}$ \\
Rail cant & $1 / 40$ & - \\
\hline
\end{tabular}

This paper develops the relevant computer code in order to solve the optimization of rail profiles. Figure 4 shows the flow chart of the optimization algorithm.

2.4. Optimization Results. A case study is based on a standard design CN60-1100-1:18 turnout (curve radius $1100 \mathrm{~m}$, turnout angle 1:18). See Table 1 for the key parameters of switch panel; for other structural parameters, see [29], which will not be repeated here. As shown in Table 1 , Section B is $10.962 \mathrm{~m}$ from the point of switch rail.

Figure 5 shows the wheel-rail contact points distribution at four consecutive positions along the direction of the railway line. The range of lateral wheel set displacement is from $-8 \mathrm{~mm}$ to $8 \mathrm{~mm}$, and the wheel tread is LMA. When $x=5.4 \mathrm{~m}$, all the wheel-rail contact points are located on the stock rail, and when $x=5.5 \mathrm{~m}$, part of contact points are transferred from the stock rail to the switch rail. According to the calculation method, Section $\mathrm{C}$ is $5.4 \mathrm{~m}$ from the point of switch rail.

The range of lateral wheel set displacement is from $-12 \mathrm{~mm}$ to $12 \mathrm{~mm}$, and the calculated step length is adopted as $0.5 \mathrm{~mm}$. In the constraint condition of optimization, the optimized capacity of parameter $v_{i}$ is adopted as $0.5 \mathrm{~mm}$. The number of the moving points is $14[5,9]$. The straight stock rail profile at Section $\mathrm{C}$ is optimized according to the method which is described in Section 2.3. For the comparison between the rail profiles obtained before and after the optimization of the straight stock rail side at Section $\mathrm{C}$, see Figure 6 . Furthermore, the CPU time taken by the optimization algorithm to solve the case in Figure 6 using a conventional desktop with $3.2 \mathrm{GHz}$ processor is $629.31 \mathrm{~s}$. It should also be noted that the optimization algorithm is coded as a Matlab function.

\section{Calculation of Wheel-Rail Contact Geometry}

The calculation process for wheel-rail contact geometric parameters was developed based on the principle of the trace line method [23]. The wheel-rail contact geometric parameters with nominal profiles and optimized profiles were first calculated and then the influence of the optimized profile on the wheel-rail contact position and RRD was analysed in this section.

3.1. Contact Distribution of Section C. The wheel-rail contact distribution of Section $C$ with a nominal profile is shown (Figure 7). In the calculation process, the lateral displacement range of the wheel set is from $-12 \mathrm{~mm}$ to $12 \mathrm{~mm}$ and the calculation step is $0.5 \mathrm{~mm}$. The direction is positive when the wheel set moves to the switch rail.

With the nominal profile, Figure 7 indicates that when the lateral displacement of wheel set is 0 , the $y$ coordinate of the wheel-rail contact point on straight stock rail is -752.9 . With the lateral displacement of wheel set changes from $-4 \mathrm{~mm}$ to $4 \mathrm{~mm}$, the $y$ coordinate of the wheel-rail points on the left wheel is changed from -742.3 to -757.0 , and the possible 


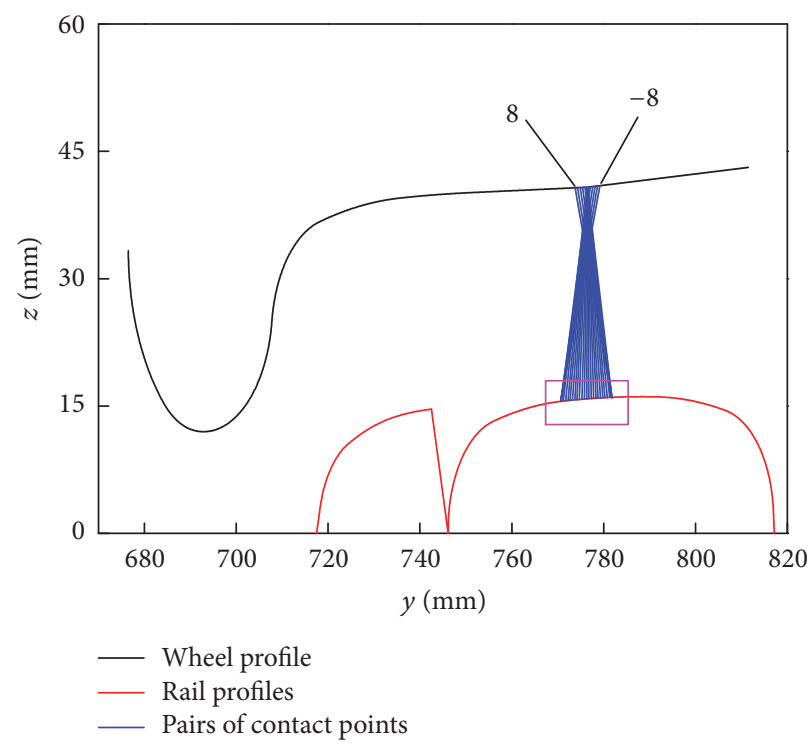

(a)

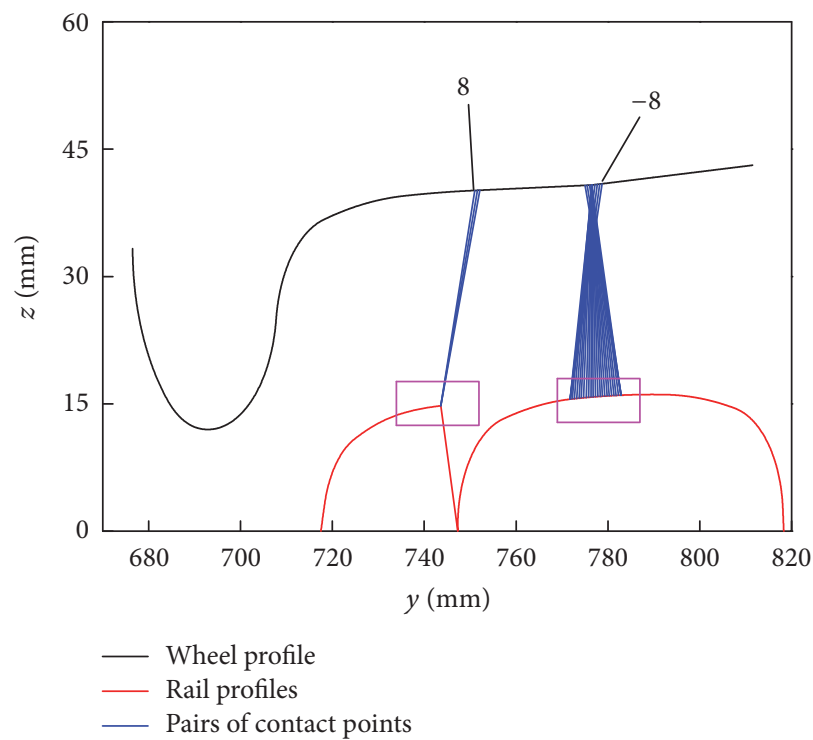

(c)

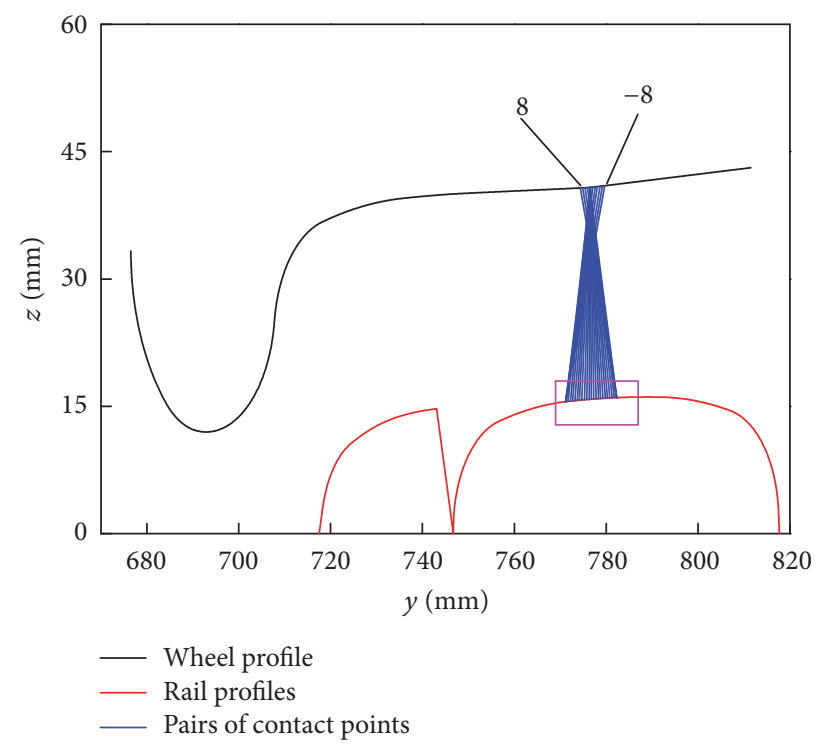

(b)

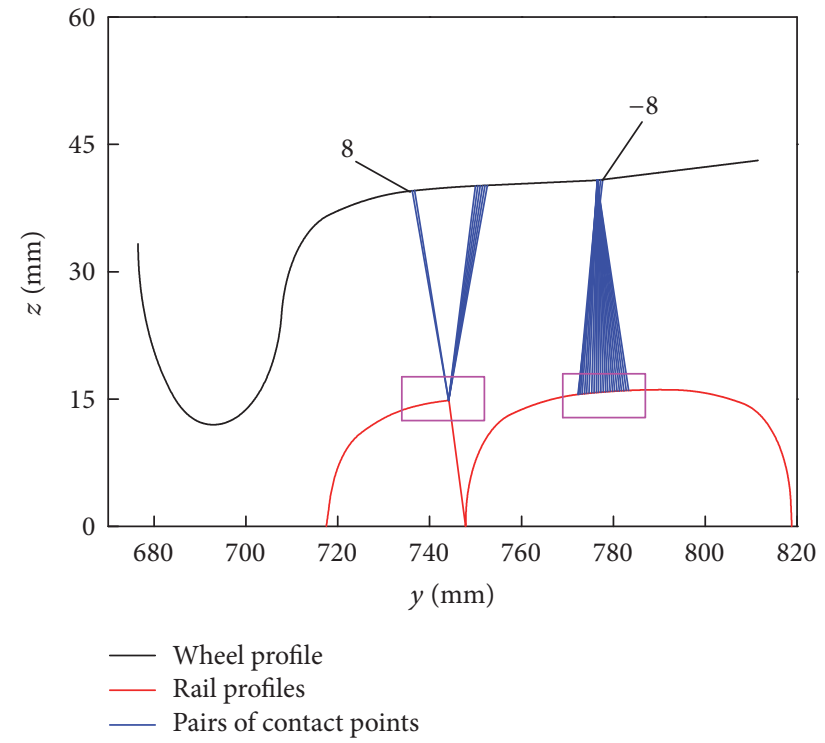

(d)

FIGURE 5: Distribution of wheel-rail contact points at different longitudinal positions. (a) $x=5.3 \mathrm{~m}$, (b) $x=5.4 \mathrm{~m}$, (c) $x=5.5 \mathrm{~m}$, and (d) $x=5.6 \mathrm{~m}$.

wheel-rail contact width on the wheel is $14.7 \mathrm{~mm}$. The wheelrail contact distribution of Section $\mathrm{C}$ with an optimized profile is schematically shown (Figure 8).

With the optimized profile, when the lateral displacement of wheel set is 0 , the $y$ coordinate of the wheel-rail contact point on straight stock rail is -759.1 . With the lateral displacement of wheel set changes from $-4 \mathrm{~mm}$ to $4 \mathrm{~mm}$, the $y$ coordinate of the wheel-rail points on the left wheel is changed from -754.3 to -762.0 , and the possible wheelrail contact width on the wheel is $7.7 \mathrm{~mm}$. The optimized profile has little influence on the wheel-rail contact point distribution at the switch rail side (right side). The position of wheel-rail contact points at the straight stock rail (left side) moves to the outside of the rail, and the movement value is around $6.2 \mathrm{~mm}$. When the lateral displacement of wheel set is kept within $-4 \mathrm{~mm}-4 \mathrm{~mm}$, the possible wheel-rail contact width at the straight stock rail side with optimized profile will be reduced from $14.7 \mathrm{~mm}$ to $7.7 \mathrm{~mm}$. The contact point distribution on the wheel is more centralized, which, to a certain extent, is good for improving the running stability of wheel set.

3.2. Contact Point Position on Wheels. As mentioned in Section 2.1, for the switch panel of railway turnout, the change of wheel-rail contact points at the switch rail side will cause 


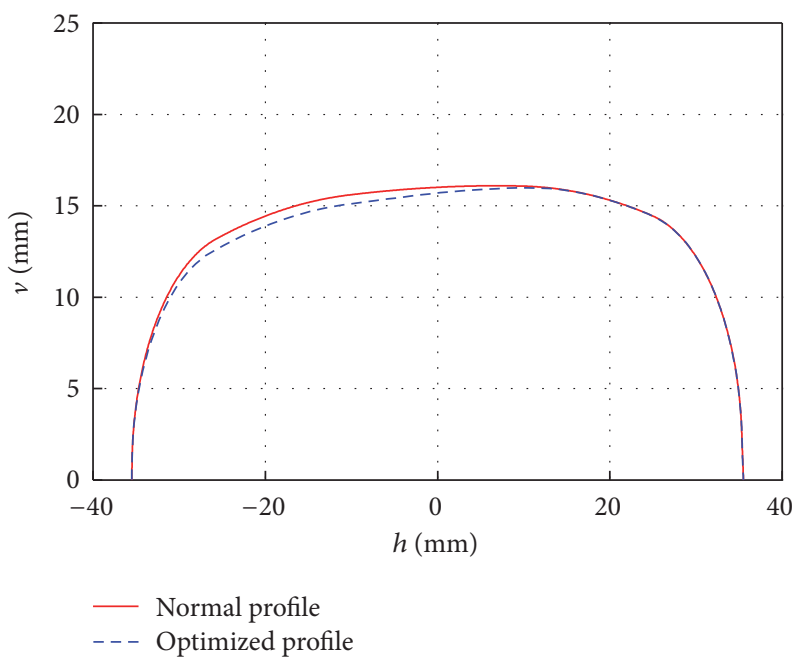

Figure 6: Optimized rail profile for Section C.

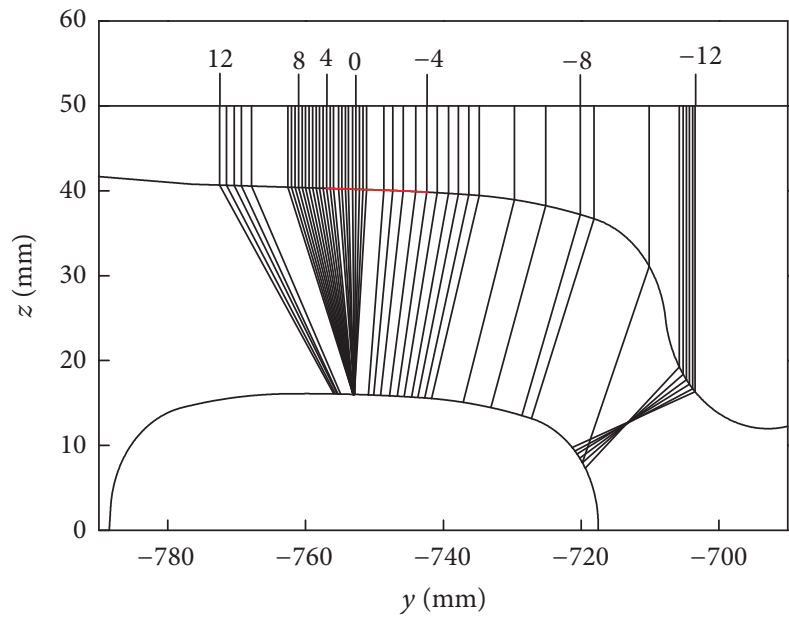

(a)

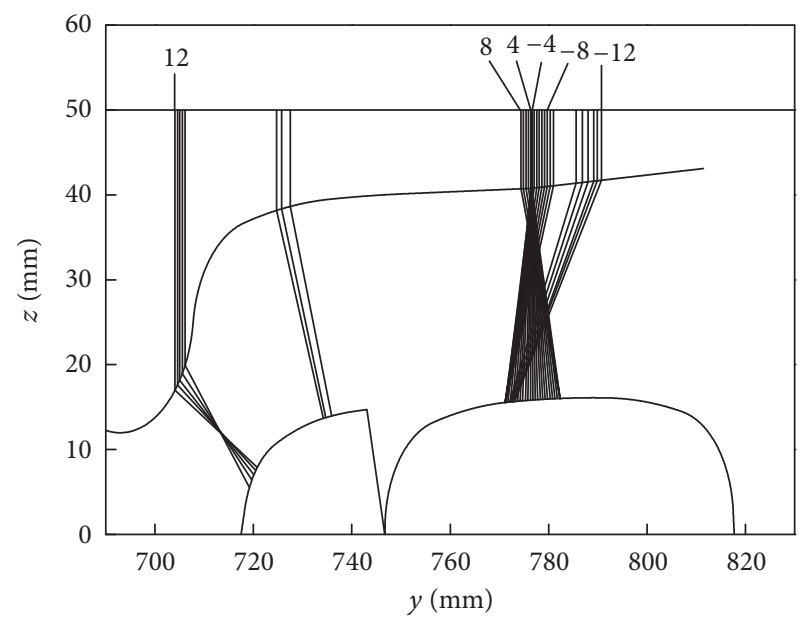

(b)

Figure 7: Contact distribution with nominal profile. (a) Stock rail and (b) switch rails. The red solid line represents the possible wheel-rail contact range on wheel with the lateral wheel set displacement from $-4 \mathrm{~mm}$ to $4 \mathrm{~mm}$.

RRD of wheel set. The more the contact points at both sides of the wheels deviate, the lower the wheel set running stability will become. So in this paper, the influence of optimized profile on the wheel set running stability can be evaluated roughly through calculating the contact point distribution at both sides of the wheels along the longitudinal direction of the railway line without lateral displacement of wheel set. Figure 9 shows the law of changing contact point positions on wheels along the longitudinal direction of the railway line under the comparison between nominal and optimized profile.

The optimized profiles have little influence on the wheelrail contact points at the switch rail side, while the contact points at the straight stock rail side are closer to the outside of the wheels. For nominal profiles, the maximum distance between the contact points of wheels at both sides is
$23.9 \mathrm{~mm}$, while for optimized profiles, the maximum distance is $17.5 \mathrm{~mm}$, decreasing by $26.8 \%$.

3.3. Rolling Radii Difference. As shown in Figure 10, the RRD of wheel set in a contour plot is shown as a function of wheel set distance from the point of the switch rail and lateral displacement of the wheel set. In the calculation process, the lateral displacement range of the wheel set is from $-8 \mathrm{~mm}$ to $8 \mathrm{~mm}$ and the calculation step is $0.5 \mathrm{~mm}$. In addition, the lateral displacement is positive when the wheel set moves to the switch rail.

The figure illustrates that the RRD of wheel set decreases with the optimized profiles. When the lateral displacement of wheel set is changed from $-8 \mathrm{~mm}$ to $8 \mathrm{~mm}$, for the optimized profiles, the maximum RRD of wheel set can be reduced from 


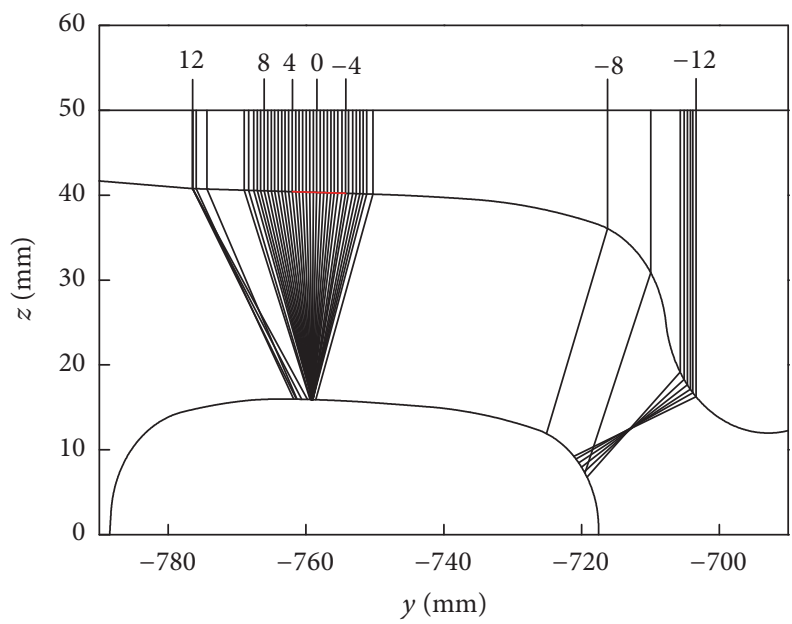

(a)

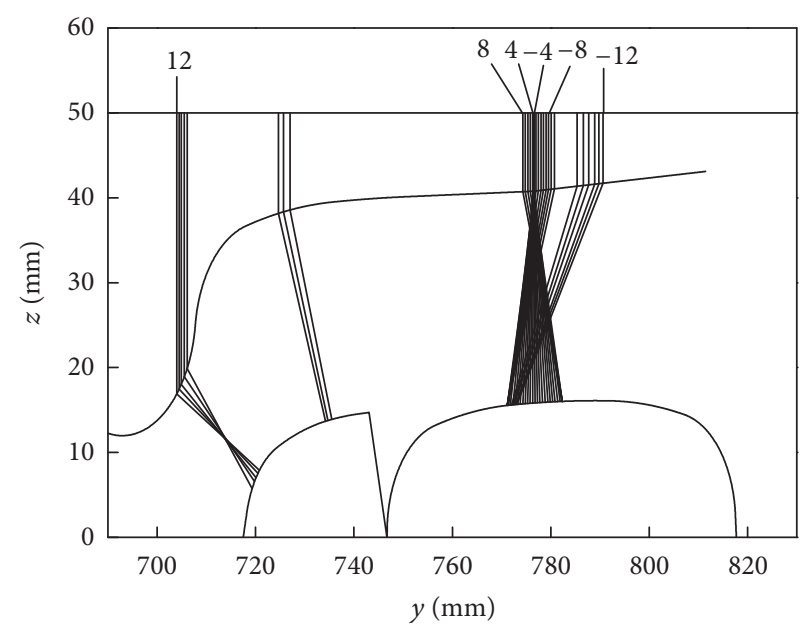

(b)

FIGURE 8: Contact distribution with optimized profile. (a) Stock rail and (b) switch rails. The red solid line represents the possible wheel-rail contact range on wheel with the lateral wheel set displacement from $-4 \mathrm{~mm}$ to $4 \mathrm{~mm}$.

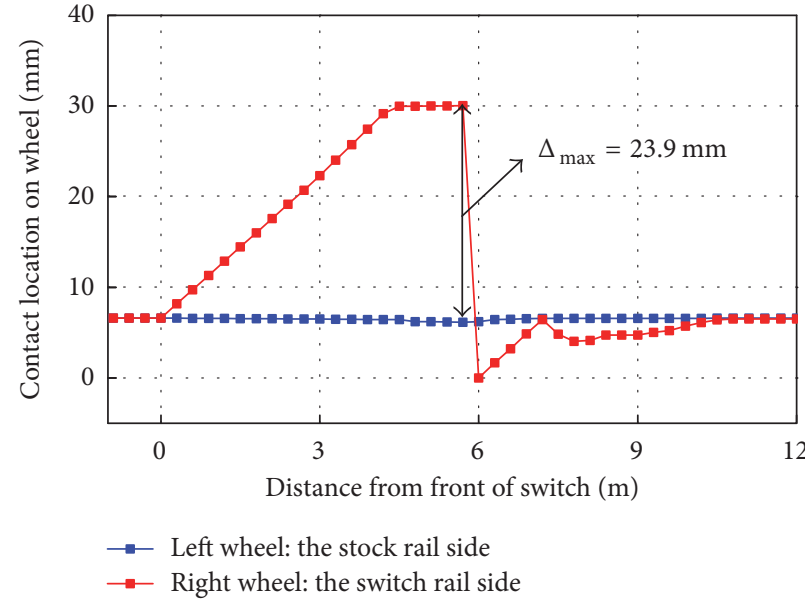

(a)

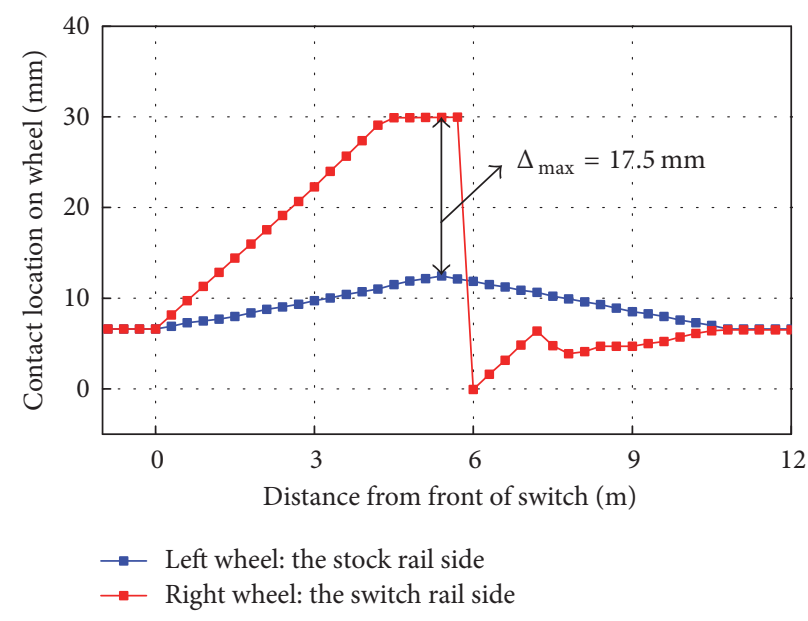

(b)

Figure 9: Distribution of wheel-rail contact points without lateral wheel set displacement. (a) Nominal profile and (b) optimized profile. As the value of the vertical axis increases, the contact point will come closer to the outside of wheels.

$3.8 \mathrm{~mm}$ to $3.1 \mathrm{~mm}$. Without the lateral displacement of wheel set, the maximum RRD in relation to a nominal profile will be kept within $0.5 \mathrm{~mm}-1 \mathrm{~mm}$, while that in relation to an optimized profile will be kept within $0.3 \mathrm{~mm}-0.5 \mathrm{~mm}$.

\section{Dynamic Interactions of Vehicle and Turnout}

4.1. Calculation Model. The vehicle-turnout dynamic interaction is simulated in the validated commercial software Simpack. The calculation model includes two interactive parts: a three-dimensional multibody model of the Chinese high-speed vehicle CRH2 (Figure 11) and a space-dependent model of the railway turnout with a flexible track foundation (Figure 12), which are connected by a local model of the $\mathrm{w} / \mathrm{r}$ contact [30].
The calculation model of the vehicle includes modelling of the car body, suspension elements, bogies, and wheelsets. In this paper, a three-dimensional multibody model of the vehicle is implemented. The car body, bogie frames, and the wheelsets are modelled as rigid bodies. The parameter values of the vehicle model are listed below (Table 2). The simulated turnout model is based on a standard design CN60-11001:18 (curve radius $1,100 \mathrm{~m}$ with a turnout angle $1: 18$ ). The varied rail profiles are realised by sampling several cross sections of the switch rail at certain positions along the switch panel. Furthermore, the specific features of the switch panel, such as sudden changes of track curvature due to the absence of transition curves, cant deficiency, and variations in rail cross section, are considered. In the $\mathrm{w} / \mathrm{r}$ contact model, the Hertz contact theory is applied for calculation of the normal contact force, and the FASTSIM algorithm 


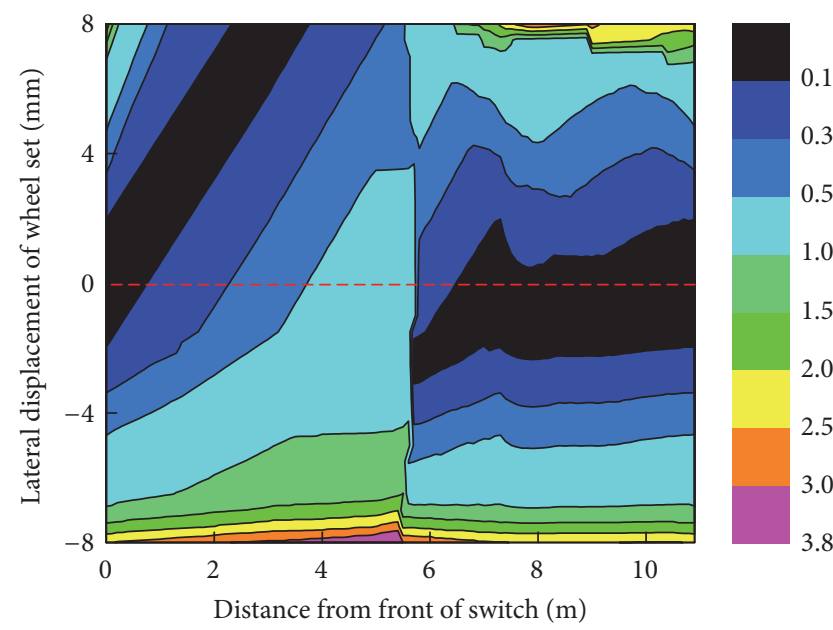

(a)

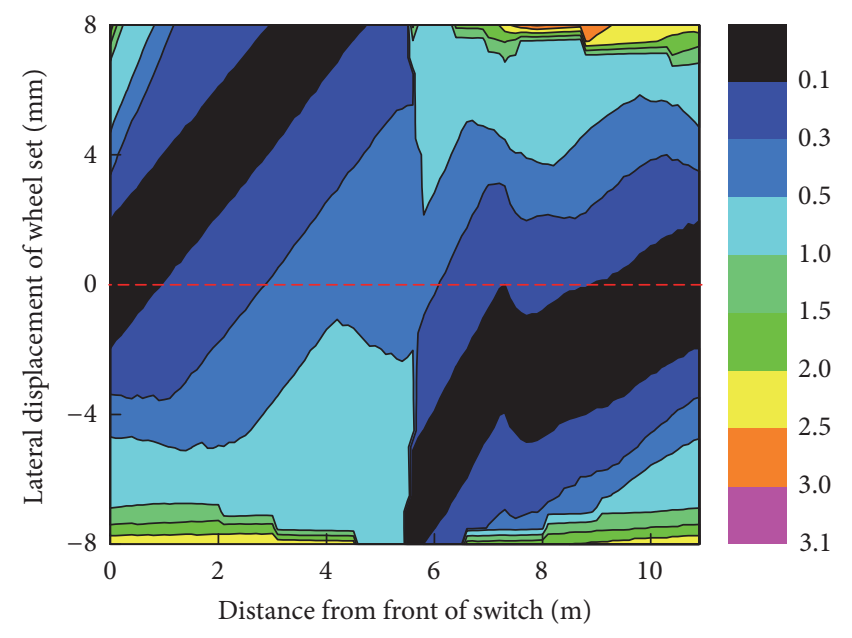

(b)

FIGURE 10: Contour plot of RRD ( $\mathrm{mm}$ ) showing the lateral displacement of the wheel set versus the distance from the point of the switch rail. (a) Nominal profile and (b) optimized profile.

TABLE 2: Parameter values of vehicle model.

\begin{tabular}{|c|c|c|}
\hline Parameters & Value & Unit \\
\hline The mass of car body & 42,400 & $\mathrm{~kg}$ \\
\hline The rolling moment of inertia of car body & $7.06 e 5$ & $\mathrm{~kg} \cdot \mathrm{m}^{2}$ \\
\hline The nodding moment of inertia of car body & $2.27 e 6$ & $\mathrm{~kg} \cdot \mathrm{m}^{2}$ \\
\hline The yawing moment of inertia of car body & $2.08 e 6$ & $\mathrm{~kg} \cdot \mathrm{m}^{2}$ \\
\hline The mass of bogie & 3,100 & $\mathrm{~kg}$ \\
\hline The rolling moment of inertia of bogie & 5,045 & $\mathrm{~kg} \cdot \mathrm{m}^{2}$ \\
\hline The nodding moment of inertia of bogie & 2,806 & $\mathrm{~kg} \cdot \mathrm{m}^{2}$ \\
\hline The yawing moment of inertia of bogie & 2,247 & $\mathrm{~kg} \cdot \mathrm{m}^{2}$ \\
\hline The mass of wheel set & 1,850 & $\mathrm{~kg}$ \\
\hline The rolling moment of inertia of wheel set & 717 & $\mathrm{~kg} \cdot \mathrm{m}^{2}$ \\
\hline The yawing moment of inertia of wheel set & 717 & $\mathrm{~kg} \cdot \mathrm{m}^{2}$ \\
\hline Half of longitudinal stiffness of secondary suspension & $1.45 e 5$ & $\mathrm{~N} / \mathrm{m}$ \\
\hline Half of lateral stiffness of secondary suspension & $2.05 e 5$ & $\mathrm{~N} / \mathrm{m}$ \\
\hline Half of vertical stiffness of secondary suspension & $1.48 e 5$ & $\mathrm{~N} / \mathrm{m}$ \\
\hline Half of longitudinal damping of secondary suspension & $3.43 e 5$ & $\mathrm{~N} \cdot \mathrm{s} / \mathrm{m}$ \\
\hline Half of lateral damping of secondary suspension & $2.45 e 4$ & $\mathrm{~N} \cdot \mathrm{s} / \mathrm{m}$ \\
\hline Half of vertical damping of secondary suspension & $3.16 e 4$ & $\mathrm{~N} \cdot \mathrm{s} / \mathrm{m}$ \\
\hline Half of longitudinal stiffness of primary suspension & $2.80 e 7$ & $\mathrm{~N} / \mathrm{m}$ \\
\hline Half of lateral stiffness of primary suspension & $2.80 e 7$ & $\mathrm{~N} / \mathrm{m}$ \\
\hline Half of vertical stiffness of primary suspension & $2.80 e 7$ & $\mathrm{~N} / \mathrm{m}$ \\
\hline Half of lateral damping of primary suspension & $1.77 e 4$ & $\mathrm{~N} \cdot \mathrm{s} / \mathrm{m}$ \\
\hline The vertical distance between mass centre of vehicle body and secondary suspension & 1.100 & $\mathrm{~m}$ \\
\hline The vertical distance between secondary suspension and mass centre of bogie & 0.100 & $\mathrm{~m}$ \\
\hline The vertical distance between mass centre of bogie and primary suspension & 0.270 & $\mathrm{~m}$ \\
\hline Half of lateral distance between primary suspensions & 0.813 & $\mathrm{~m}$ \\
\hline Half of lateral distance between secondary suspensions & 0.978 & $\mathrm{~m}$ \\
\hline Half of bogie fixed axles distance & 1.350 & $\mathrm{~m}$ \\
\hline Half of distance between mass centres of car bodies & 8.750 & $\mathrm{~m}$ \\
\hline Nominal rolling radius of wheel & 0.430 & $\mathrm{~m}$ \\
\hline
\end{tabular}




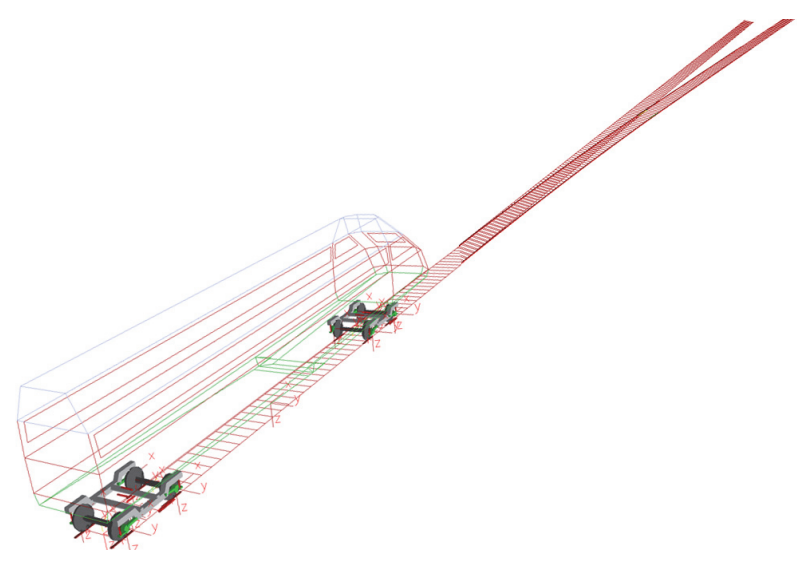

FIGURE 11: Multibody model of vehicle.

is used to solve the tangential contact problem. During the simulation calculation, a vehicle passing the switch panel in the through route with facing and trailing move is simulated, respectively.

4.2. Dynamic Responses with Facing Move. When a vehicle passes the switch panel in the through route with facing move, the effects of the optimized profile on the dynamic interaction between the vehicle and turnout are analysed, and the simulation is carried out at the speed of $350 \mathrm{~km} / \mathrm{h}$ for the vehicle. The calculation results include the vertical and lateral wheel-rail contact force at the side of the switch rail, the lateral displacement of the wheel set, and the lateral vibration acceleration of car body (the vibration acceleration is calculated at the centre of mass of the car body) (Figure 13).

The optimized profiles have a great influence on the lateral dynamic interaction between the vehicle and turnout. In the switch panel, the maximum lateral contact force is $9.4 \mathrm{kN}$ for the nominal profile and is $6.2 \mathrm{kN}$ for the optimized profile, decreasing by $34.0 \%$. The optimized profile will not greatly influence the vertical wheel-rail contact force. The maximum lateral displacement of wheel set is $4.9 \mathrm{~mm}$ for the nominal profile and is $3.1 \mathrm{~mm}$ for the optimized profile, decreasing by $36.7 \%$. The hunting motion amplitude of the wheel set in the switch panel is decreased extensively. The amplitude of the lateral acceleration of the car body is decreased by $41.9 \%$ (from $0.31 \mathrm{~m} / \mathrm{s}^{2}$ to $0.18 \mathrm{~m} / \mathrm{s}^{2}$ ).

4.3. Dynamic Responses with Trailing Move. When a vehicle passes the switch panel in the through route with trailing move, the effects of the optimized profile on the dynamic interaction between the vehicle and turnout are analysed, and the simulation is carried out at the speed of $350 \mathrm{~km} / \mathrm{h}$ for the vehicle. The content of simulation calculation is the same as that mentioned in Section 4.2. The calculation results are shown in Figure 14.

In the switch panel, the maximum lateral contact force is $7.7 \mathrm{kN}$ for the nominal profile and is $5.4 \mathrm{kN}$ for the optimized profile, decreasing by $29.9 \%$. The optimized profile will not greatly influence the vertical wheel-rail contact force. The

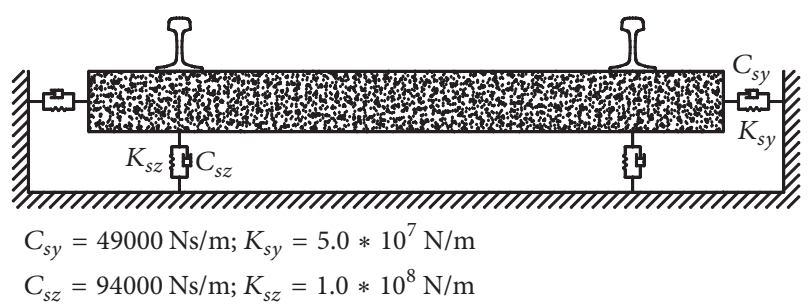

FIGURE 12: Track foundation of flexibility.

maximum lateral displacement of wheel set is $4.8 \mathrm{~mm}$ for the nominal profile and is $3.3 \mathrm{~mm}$ for the optimized profile, decreasing by $31.3 \%$. The hunting motion amplitude of the wheel set in the switch panel is decreased extensively. The amplitude of the lateral acceleration of the car body is decreased by $40.7 \%$ (from $0.27 \mathrm{~m} / \mathrm{s}^{2}$ to $0.16 \mathrm{~m} / \mathrm{s}^{2}$ ). Overall, the optimized profiles have a great influence on the lateral dynamic interaction between the vehicle and turnout, and the lateral stability of the vehicle is improved obviously by the optimized design.

\section{Conclusions}

In this paper, a method for optimization of rail profiles to improve vehicle stability in switch panel of high-speed railway turnouts is presented, the effects of optimized profile on the $\mathrm{w} / \mathrm{r}$ contact geometric parameters and dynamic interaction of vehicle and turnout are simulated, and both nominal and optimized profiles are taken as inputs for the simulation. The optimized profile strongly improves the lateral dynamic interaction of vehicle and turnout. The outcome of this paper could provide some theoretical guidance for the grinding of switch rail profiles and modify the dynamic performance of the vehicle, thus increasing ride quality. According to the results, the following can be summarized:

(1) The optimized profile of Section C has little influence on the wheel-rail contact point distribution at the switch rail side. The position of wheel-rail contact points at the straight stock rail moves to the outside of the rail, and the maximum movement value is around $6.2 \mathrm{~mm}$. When the lateral displacement of wheel set is kept within $-4 \mathrm{~mm}-4 \mathrm{~mm}$, the possible wheel-rail contact width at the straight stock rail side with optimized profile will be reduced from $14.7 \mathrm{~mm}$ to $7.7 \mathrm{~mm}$. The contact point distribution on the wheel is more centralized, which is good for improving the running stability of wheel set.

(2) When the lateral displacement of wheel set is changed from $-8 \mathrm{~mm}$ to $8 \mathrm{~mm}$, for the optimized profiles, the maximum RRD of wheel set can be reduced from $3.8 \mathrm{~mm}$ to $3.1 \mathrm{~mm}$. Without the lateral displacement of wheel set, the maximum RRD in relation to a nominal profile will be kept within $0.5 \mathrm{~mm}-1 \mathrm{~mm}$, while that in relation to an optimized profile will be kept within 


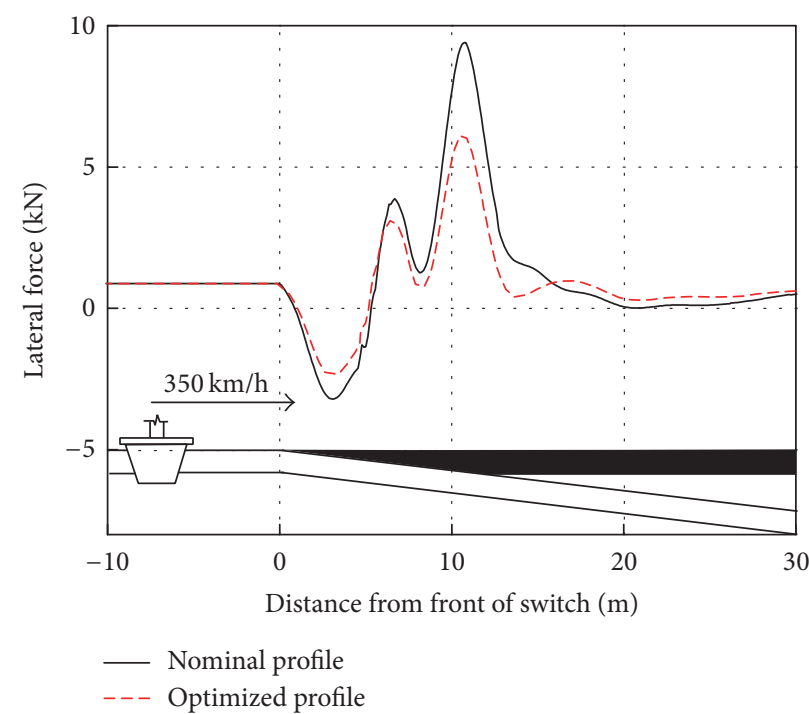

(a)

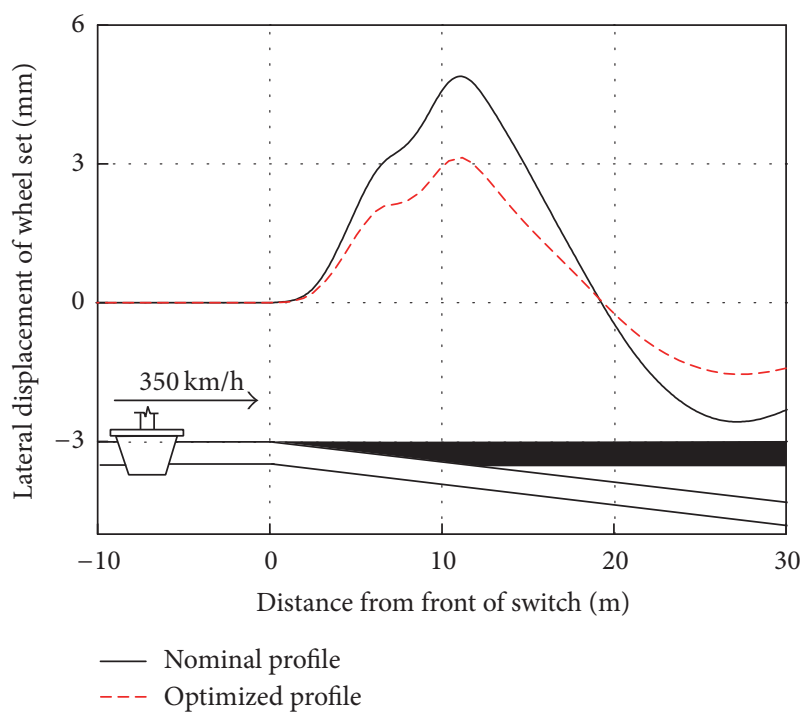

(c)

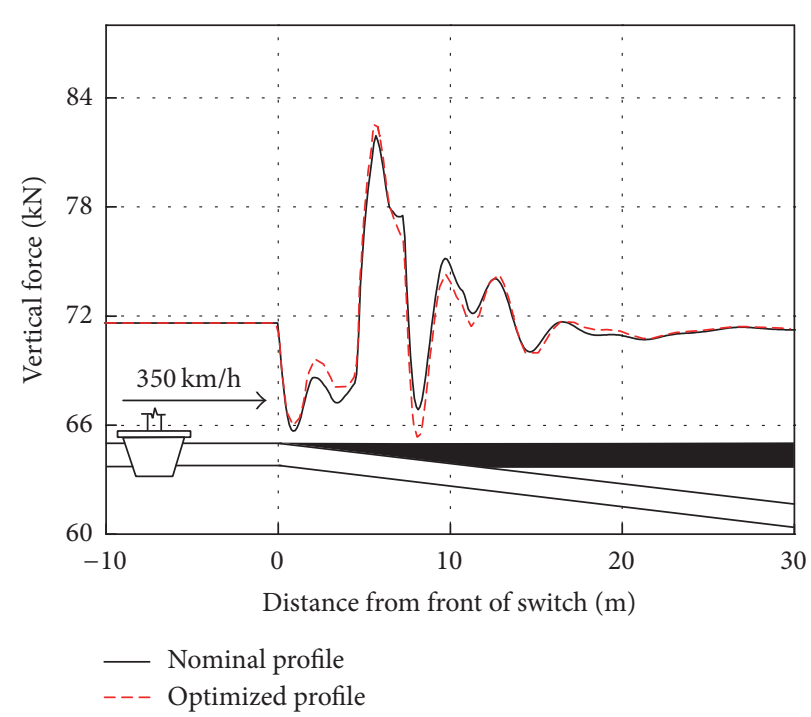

(b)

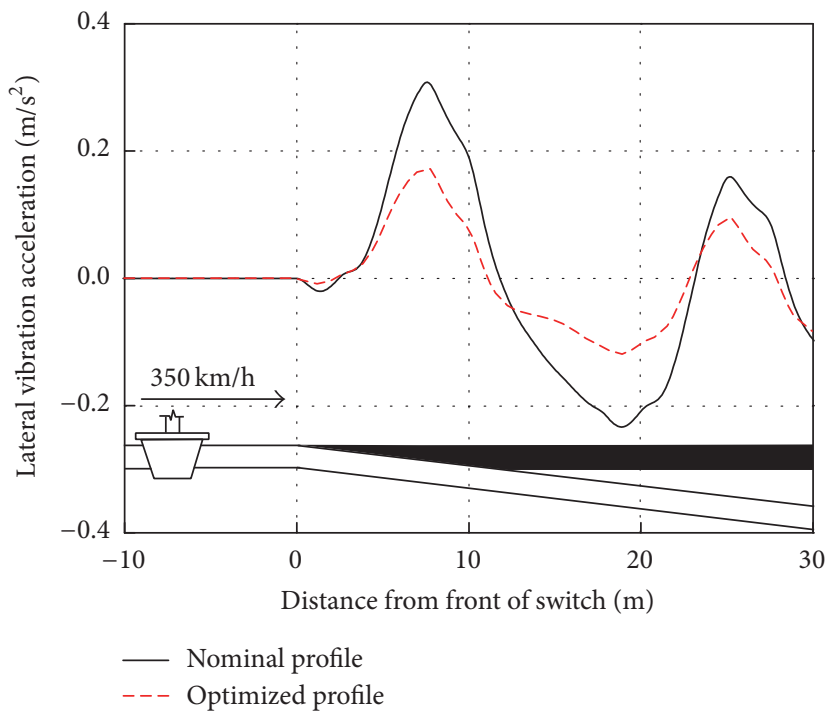

(d)

FIGURE 13: The comparison of dynamic interaction with facing move. (a) Lateral contact force, (b) vertical contact force, (c) lateral displacement of wheel set, and (d) lateral acceleration of car body.

$0.3 \mathrm{~mm}-0.5 \mathrm{~mm}$. The RRD of wheel set is decreased with the optimized profile.

(3) When a vehicle passes the switch panel in the through route with facing move, the maximum lateral contact force is $9.4 \mathrm{kN}$ for the nominal profile and is $6.2 \mathrm{kN}$ for the optimized profile, decreasing by $34.0 \%$. The optimized profile will not greatly influence the vertical wheel-rail contact force. The maximum lateral displacement of wheel set is $4.9 \mathrm{~mm}$ for the nominal profile and is $3.1 \mathrm{~mm}$ for the optimized profile, decreasing by $36.7 \%$. The amplitude of the lateral acceleration of the car body is decreased by $41.9 \%$ (from $0.31 \mathrm{~m} / \mathrm{s}^{2}$ to $0.18 \mathrm{~m} / \mathrm{s}^{2}$ ).
(4) When a vehicle passes the switch panel in the through route with trailing move, the maximum lateral contact force is $7.7 \mathrm{kN}$ for the nominal profile and is $5.4 \mathrm{kN}$ for the optimized profile, decreasing by $29.9 \%$. The optimized profile will not greatly influence the vertical wheel-rail contact force. The maximum lateral displacement of wheel set is $4.8 \mathrm{~mm}$ for the nominal profile and is $3.3 \mathrm{~mm}$ for the optimized profile, decreasing by $31.3 \%$. The amplitude of the lateral acceleration of the car body is decreased by $40.7 \%$ (from $0.27 \mathrm{~m} / \mathrm{s}^{2}$ to $0.16 \mathrm{~m} / \mathrm{s}^{2}$ ).

The profile optimization of the railway turnout is a longterm and complicated process, and different objectives should 


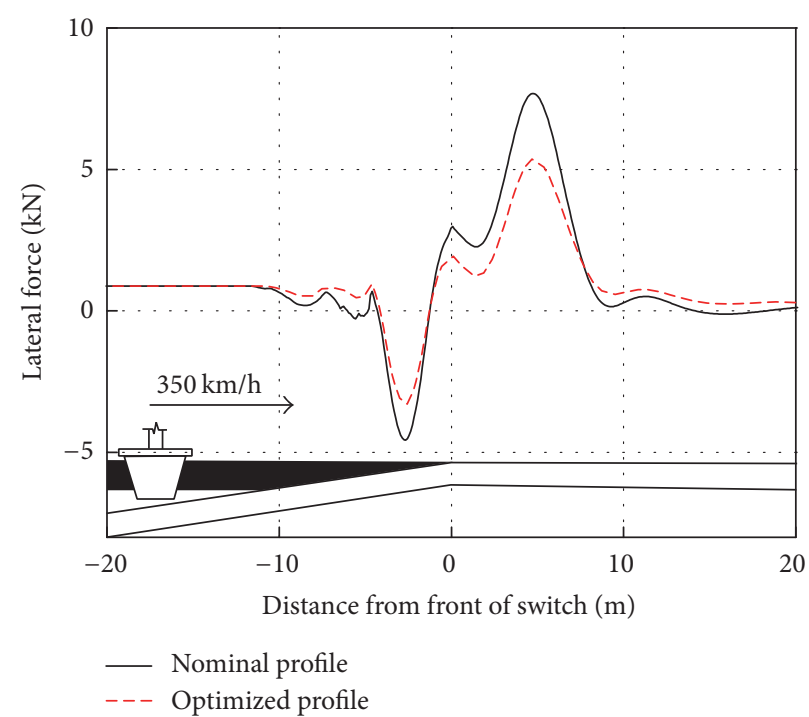

(a)

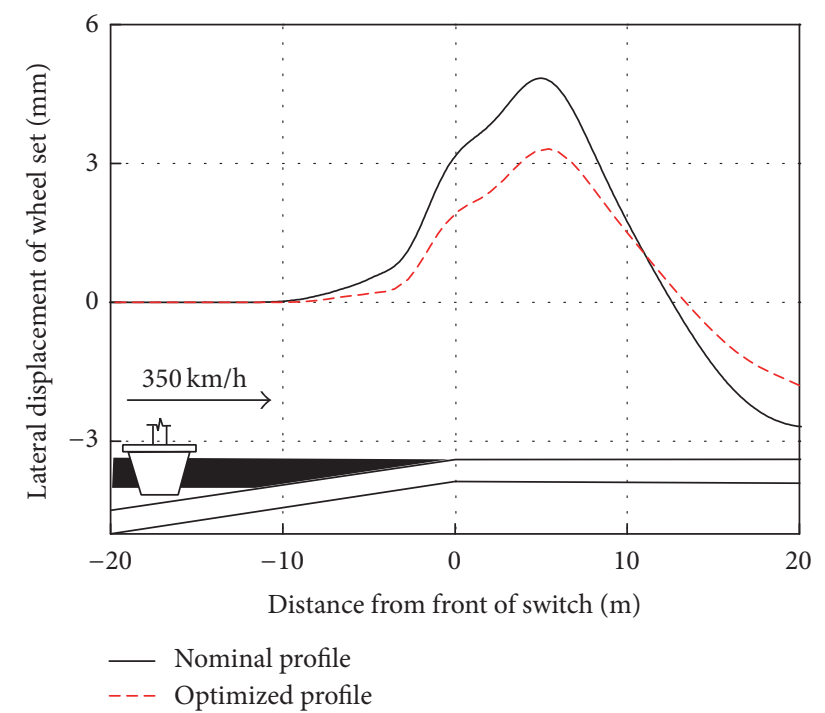

(c)

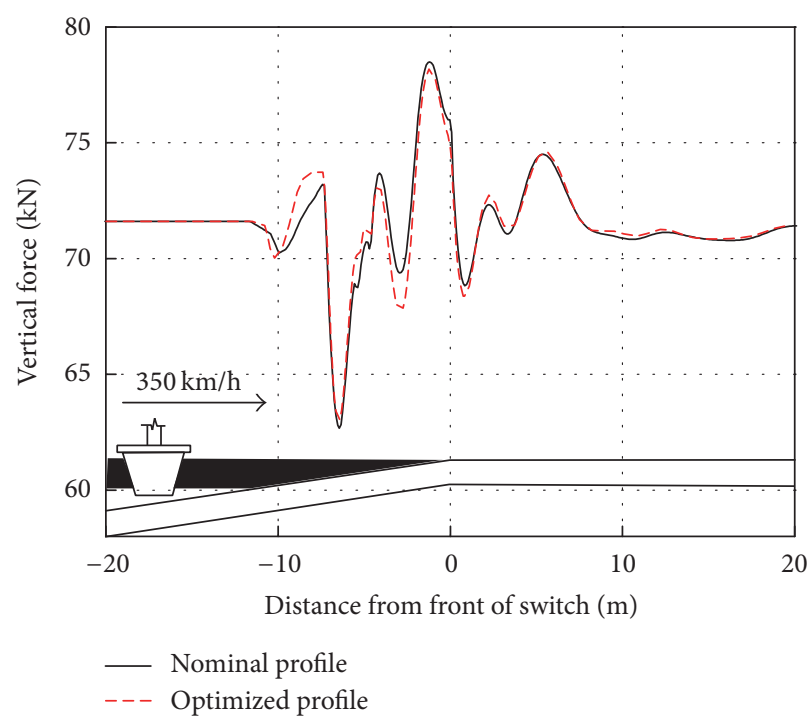

(b)

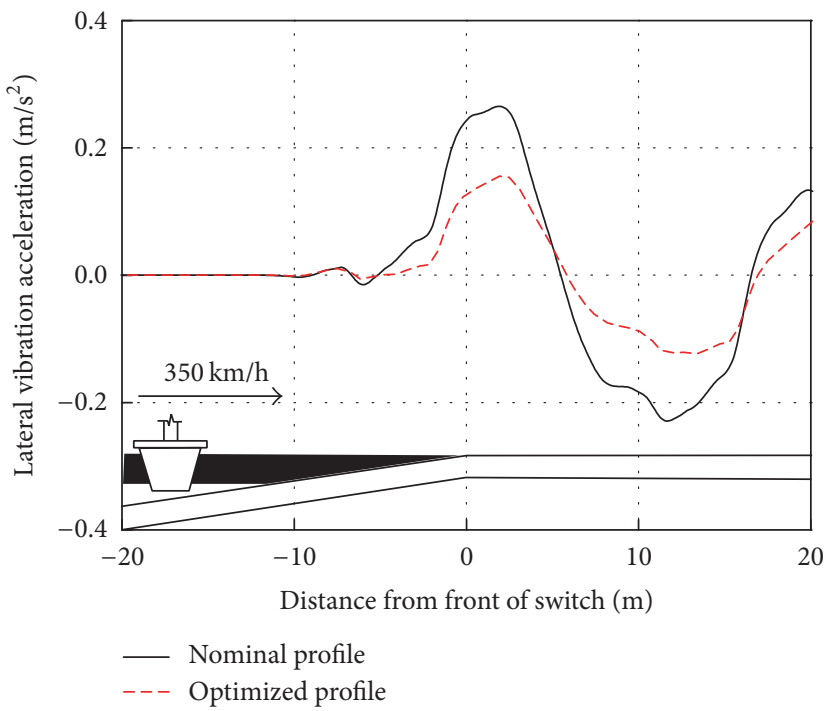

(d)

FIGURE 14: The comparison of dynamic interaction with trailing move. (a) Lateral contact force, (b) vertical contact force, (c) lateral displacement of wheel set, and (d) lateral acceleration of car body.

be chosen under different conditions in the optimal design. For example, the stability of the vehicle is the most important in high-speed railway turnout; therefore, an optimal design method is presented in this paper based on the objective that can decrease the amplitude of hunting motion of the wheel set in the switch panel. In the heavy-haul railway turnout, the wear problem of the wheel and rail is the focus in optimized research. Since the speed of the vehicle when passing the turnout in the through route is much faster than diverging line, therefore the requirement of vehicle running stability in the through route is stricter. The optimization method in this paper is presented to improve vehicle running stability in the through route, the influence of optimized profiles on vehicle running stability in diverging line is not considered, and it will be considered in the future work if necessary.

\section{Competing Interests}

The authors declared that there is no conflict of interests in their submitted paper.

\section{Acknowledgments}

The present work has been supported by the National Natural Science Foundation of China (51425804 and 51608459), the Key Project of the China's High-Speed Railway United Fund (U1234201), and the Science and Technology Project of China Railway Corporation (2015G006-C) and thanks are due to the support with the Doctoral Dissertation Cultivation Project of Southwest Jiaotong University (2015). 


\section{References}

[1] E. Kassa, C. Andersson, and J. C. O. Nielsen, "Simulation of dynamic interaction between train and railway turnout," Vehicle System Dynamics, vol. 44, no. 3, pp. 247-258, 2006.

[2] N. Burgelman, Z. Li, and R. Dollevoet, "A new rolling contact method applied to conformal contact and the train-turnout interaction," Wear, vol. 321, pp. 94-105, 2014.

[3] I. Y. Shevtsov, V. L. Markine, and C. Esveld, "Optimal design of wheel profile for railway vehicles," Wear, vol. 258, no. 7-8, pp. 1022-1030, 2005.

[4] I. Y. Shevtsov, V. L. Markine, and C. Esveld, "Design of railway wheel profile taking into account rolling contact fatigue and wear," Wear, vol. 265, no. 9-10, pp. 1273-1282, 2008.

[5] H. Jahed, B. Farshi, M. A. Eshraghi, and A. Nasr, "A numerical optimization technique for design of wheel profiles," Wear, vol. 264, no. 1-2, pp. 1-10, 2008.

[6] V. L. Markine, I. Y. Shevtsov, and C. Esveld, "An inverse shape design method for railway wheel profiles," Structural and Multidisciplinary Optimization, vol. 33, no. 3, pp. 243-253, 2007.

[7] O. Polach, "Wheel profile design for target conicity and wide tread wear spreading," Wear, vol. 271, no. 1-2, pp. 195-202, 2011.

[8] G. Shen, J. B. Ayasse, H. Chollet, and I. Pratt, "A unique design method for wheel profiles by considering the contact angle function," Proceedings of the Institution of Mechanical Engineers, Part F: Journal of Rail and Rapid Transit, vol. 217, no. 1, pp. 2530, 2003.

[9] D. Cui, L. Li, X. Jin, and X. Li, "Optimal design of wheel profiles based on weighed wheel/rail gap," Wear, vol. 271, no. 1-2, pp. 218-226, 2011.

[10] D. Cui, H. Wang, L. Li, and X. Jin, "Optimal design of wheel profiles for high-speed trains," Proceedings of the Institution of Mechanical Engineers, Part F: Journal of Rail and Rapid Transit, vol. 229, no. 3, pp. 248-261, 2015.

[11] R. Smallwood, J. C. Sinclair, and K. J. Sawley, "An optimization technique to minimize rail contact stresses," Wear, vol. 144, no. 1-2, pp. 373-384, 1991.

[12] M. Novales, A. Orro, and M. R. Bugarín, "Use of a genetic algorithm to optimize wheel profile geometry," Proceedings of the Institution of Mechanical Engineers, Part F: Journal of Rail and Rapid Transit, vol. 221, no. 4, pp. 467-476, 2007.

[13] M. Ignesti, A. Innocenti, L. Marini, E. Meli, and A. Rindi, "A numerical procedure for the wheel profile optimisation on railway vehicles," Proceedings of the Institution of Mechanical Engineers, Part J: Journal of Engineering Tribology, vol. 228, no. 2, pp. 206-222, 2014.

[14] F. T. Lin, X. Q. Dong, Y. M. Wang, and C. S. Ni, "Multiobjective optimization of CRH3 EMU wheel profile," Advances in Mechanical Engineering, vol. 7, no. 1, Article ID 284043, pp. 1-8, 2015.

[15] H.-Y. Choi, D.-H. Lee, C. Y. Song, and J. Lee, "Optimization of rail profile to reduce wear on curved track," International Journal of Precision Engineering and Manufacturing, vol. 14, no. 4, pp. 619-625, 2013.

[16] H.-Y. Choi, D.-H. Lee, and J. Lee, "Optimization of a railway wheel profile to minimize flange wear and surface fatigue," Wear, vol. 300, no. 1-2, pp. 225-233, 2013.

[17] W. Zhai, J. Gao, P. Liu, and K. Wang, "Reducing rail side wear on heavy-haul railway curves based on wheel-rail dynamic interaction," Vehicle System Dynamics, vol. 52, no. 1, pp. 440454, 2014.
[18] B. A. Pålsson and J. C. O. Nielsen, "Track gauge optimisation of railway switches using a genetic algorithm," Vehicle System Dynamics, vol. 50, no. 1, pp. 365-387, 2012.

[19] B. A. Pålsson, "Optimisation of railway crossing geometry considering a representative set of wheel profiles," Vehicle System Dynamics, vol. 53, no. 2, pp. 274-301, 2015.

[20] C. Wan, V. L. Markine, and I. Y. Shevtsov, "Improvement of vehicle-turnout interaction by optimising the shape of crossing nose," Vehicle System Dynamics, vol. 52, no. 11, pp. 1517-1540, 2014.

[21] D. Nicklisch, E. Kassa, J. Nielsen, M. Ekh, and S. Iwnicki, "Geometry and stiffness optimization for switches and crossings, and simulation of material degradation," Proceedings of the Institution of Mechanical Engineers, Part F: Journal of Rail and Rapid Transit, vol. 224, no. 4, pp. 279-292, 2010.

[22] M. R. Bugarín and J.-M. García Díaz-De-Villegas, "Improvements in railway switches," Proceedings of the Institution of Mechanical Engineers, Part F: Journal of Rail and Rapid Transit, vol. 216, no. 4, pp. 275-286, 2002.

[23] Z. Li, Wheel-Rail Rolling Contact and Its Application to Wear Simulation, Delft University of Technology, Delft, The Netherlands, 2002.

[24] P. E. Gill and D. P. Robinson, "A globally convergent stabilized SQP method," SIAM Journal on Optimization, vol. 23, no. 4, pp. 1983-2010, 2013.

[25] W. Zhao, D. Song, and B. Liu, "Error bounds and finite termination for constrained optimization problems," Mathematical Problems in Engineering, vol. 2014, Article ID 158780, 10 pages, 2014.

[26] T.-W. Liu and D.-H. Li, "A cautious BFGS update for reduced Hessian SQP," Numerical Algorithms, vol. 44, no. 1, pp. 11-28, 2007.

[27] M. Liu, X. Li, and Q. Wu, "A filter algorithm with inexact line search," Mathematical Problems in Engineering, vol. 2012, Article ID 349178, 20 pages, 2012.

[28] A. F. Izmailov and M. V. Solodov, "On attraction of linearly constrained Lagrangian methods and of stabilized and quasiNewton SQP methods to critical multipliers," Mathematical Programming, vol. 126, no. 2, pp. 231-257, 2011.

[29] P. Wang, J. Xu, K. Xie, and R. Chen, "Numerical simulation of rail profiles evolution in the switch panel of a railway turnout," Wear, pp. 105-115, 2016.

[30] J. Xu, P. Wang, L. Wang, and R. Chen, "Effects of profile wear on wheel-rail contact conditions and dynamic interaction of vehicle and turnout," Advances in Mechanical Engineering, vol. 8, no. 1, pp. 1-14, 2016. 


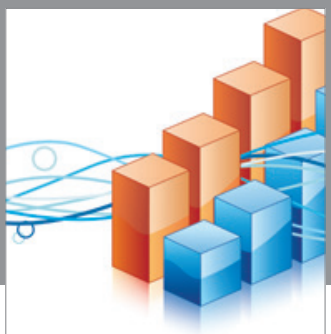

Advances in

Operations Research

vatem alat4

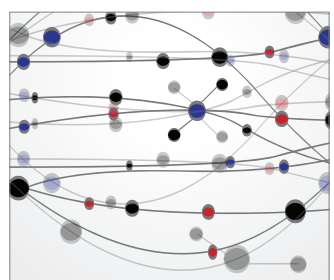

\section{The Scientific} World Journal
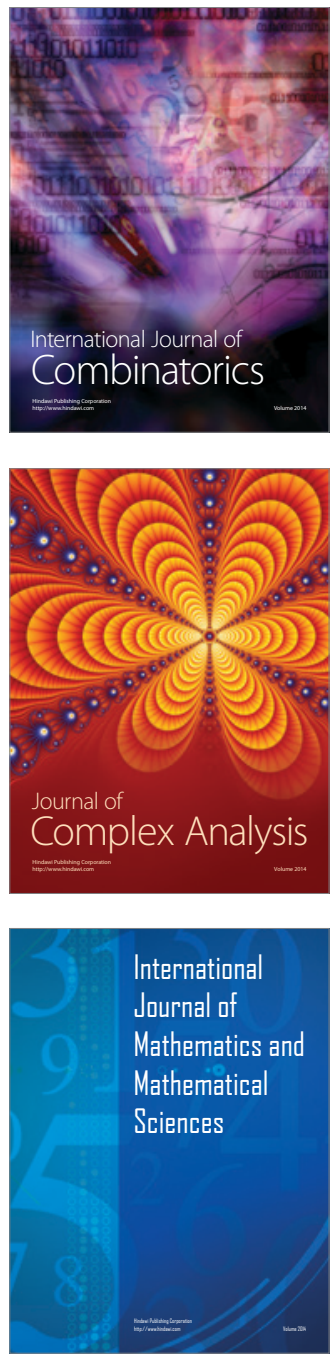
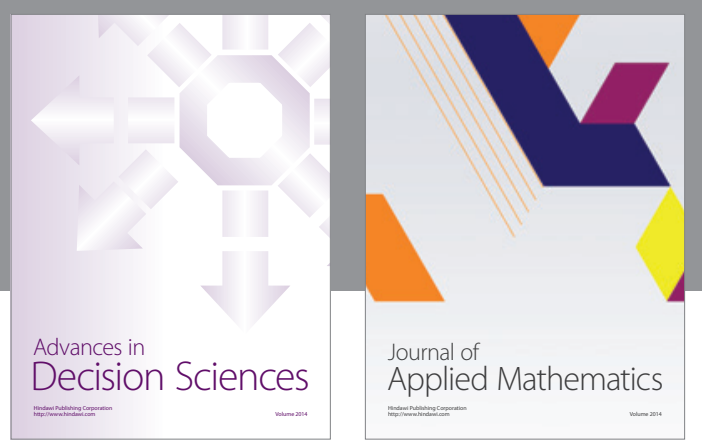

Algebra

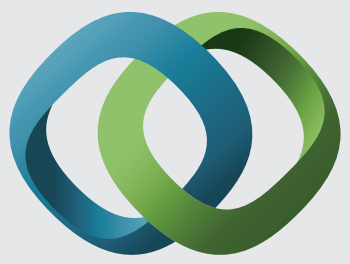

\section{Hindawi}

Submit your manuscripts at

https://www.hindawi.com
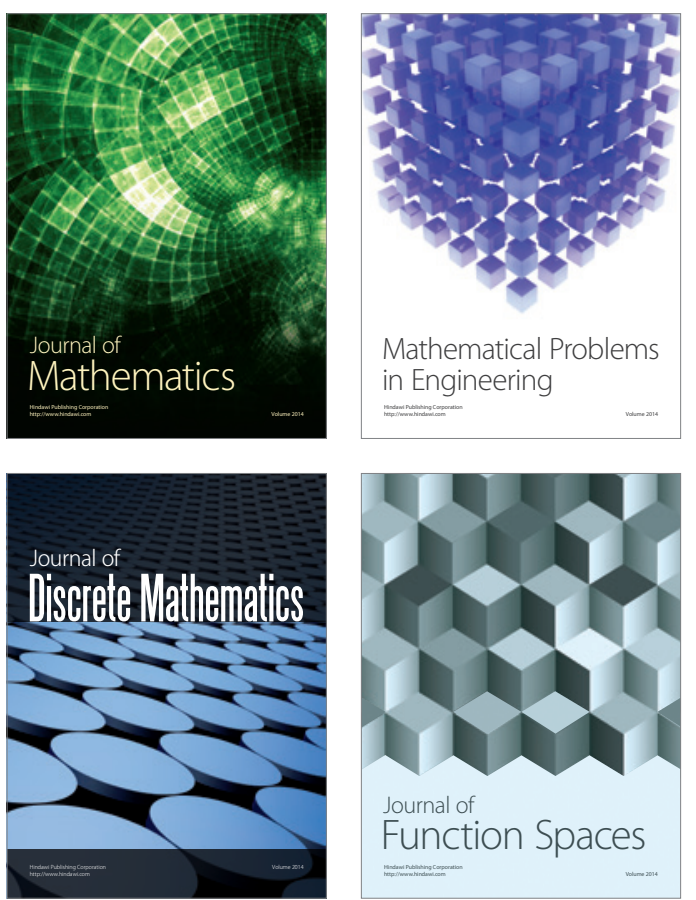

Mathematical Problems in Engineering
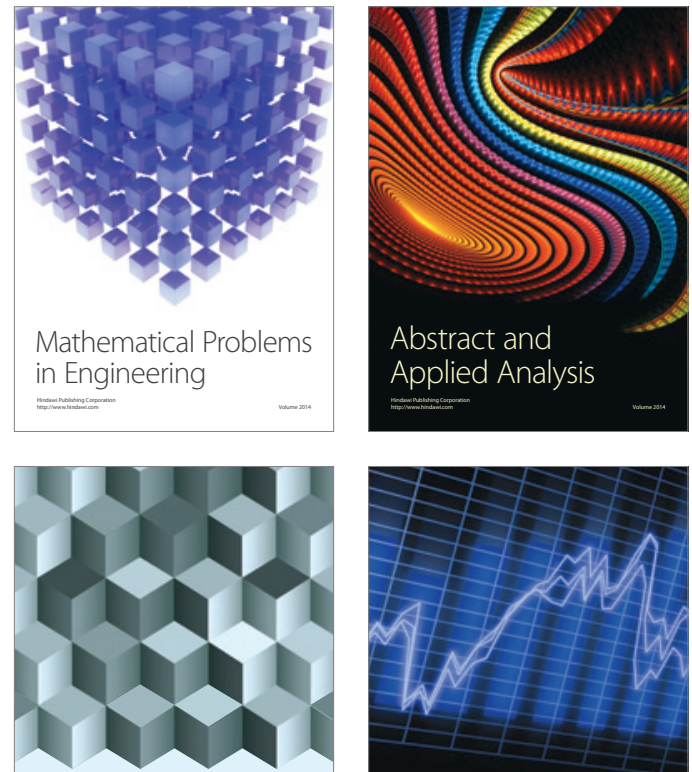

Journal of

Function Spaces

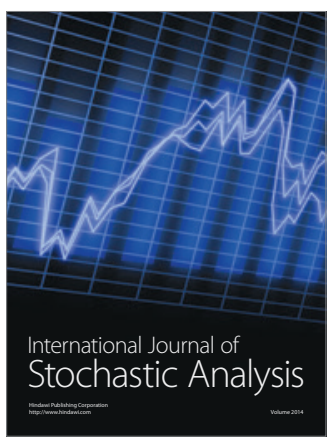

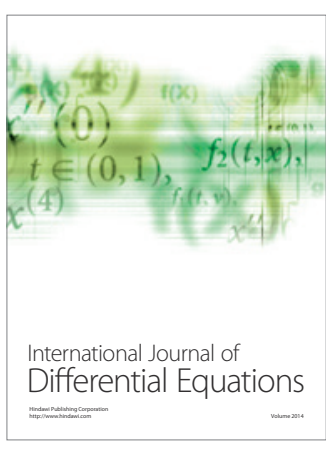
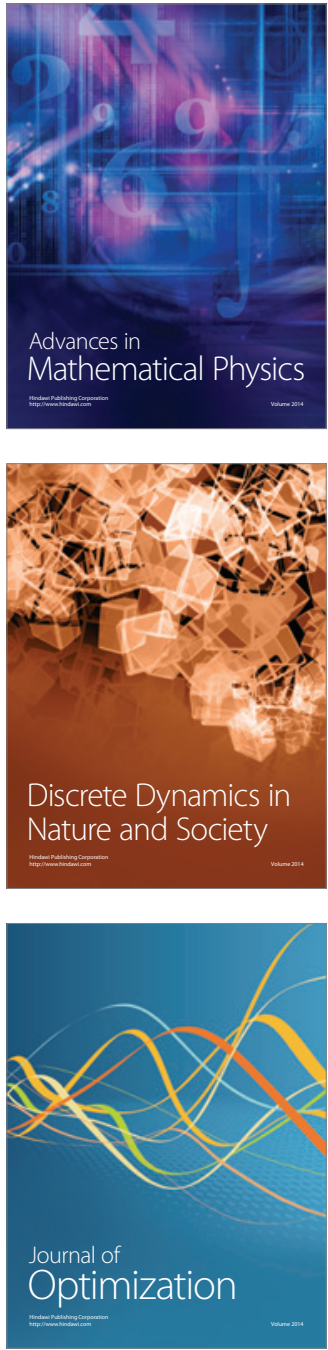